\title{
1991 E-MRS Fall Meeting Takes Multidisciplinary Look at Nuclear Waste Disposal
}

The 1991 Fall Meeting of the European Materials Research Society hosted the 15th International Symposium on the Scientific Basis for Nuclear Waste Management. Since 1982, the Symposium has been held in Europe every third year. This year for the first time the Symposium was included in an E-MRS meeting. Chaired by C.G. Sombret, (C.E.A./C.E.Valrho, 30205 Bagnols Sur Ceze, France), the Symposium was cosponsored by the Materials Research Society and the Commissariat à l'Energie Atomique of France. Support for the meeting was also provided by the Commission of the European Communities and the U.S. Department of Energy.

Perhaps the most unusual feature of this meeting was that the other symposia at the E-MRS meeting covered fields closely related to materials science issues of nuclear waste disposal. This brought together an unusually large, diverse group of researchers whose expertise has many applications in topics related to nuclear waste disposal. The other symposia included: Clays and Hydrosilicate Gels in the Nuclear Field, Solid-State Chemistry of Actinides, Chemistry of Cements for Nuclear Applications, Nuclear Materials for Fission Reactors, and Chemical Modifications Induced by Irradiation of Glasses.

Nearly 100 oral and poster presentations were made by researchers from 14 different countries. Over 250 registrants attended the nuclear waste symposium. The Plenary Session featured presentations by J. Teillac, the high commissioner of the CEA, $\mathrm{S}$. Finzi of the Commission of the European Communities, L. Duffy of the U.S. Department of Energy, J.Y. Barre, the director of the Cycle du Combustible (CEA), D. Langmuir of the U.S. Nuclear Waste Technology Review Board, and J. Cooper of the U.K. Radiological Protection Board.

The sessions spanned a wide range of materials topics: glass properties, corrosion processes and interactions with the environment, ceramics, solid-state actinide chemistry, properties and corrosion of spent fuel, canister materials, natural analogue studies, buffer and backfill materials, flow and transport in repositories. The proceedings will be published as part of the MRS Symposium Proceedings Series, Scientific Basis for Nuclear Waste Management.

Outstanding Young Scientist Awards were presented to student participants
Anette Rother, Institut für Nukleare Entsorgungstechnik (Kernforschungszentrum Karlsruhe), for her research on nuclear waste glass corrosion and to Robert Finch, University of New Mexico, for his research on the alteration of uraninite, $\mathrm{UO}_{2+\mathrm{x}}$.

The venue of the meeting, in the European Parliament and Council of Europe in Strasbourg, provided an extraordinary backdrop for the presentations. The welcoming reception and cocktail party/poster session offered many pleasant opportunities for researchers to meet and discuss their work.

The meeting was followed by a series of optional technical tours to the La Hague reprocessing plant and the Cadarache laboratory in France, the Kernforschungszentrum Karlsruhe in Germany and the Sellafield waste treatment and processing plant in the United Kingdom. This was a rare opportunity for researchers to visit nuclear research centers and reprocessing facilities. All participants judged the Symposium a success and look forward to the 1994 meeting in Japan. The Symposium returns to the United States for the 1992 and 1993 meetings. The 1992 Symposium will be held under the auspices of the Materials Research Society during the 1992 MRS Fall Meeting in Boston.

Report provided by R.C. Ewing, University of New Mexico, Dept. of Geology, Albuquerque, NM 87131, U.S.A.

\section{Clays and Hydrosilicate Gels in Nuclear Fields}

Chair: A. Meunier, Lab. de Pétrologie URA 721 CNRS, Université de Poitiers, 40, Av. du recteur Pineau, 86022 Poitiers, France.

This symposium was divided into three sessions. Of the 39 papers presented, 10 were invited. The invited papers provided up-to-date information on how we can predict the durability of the clay-engineered barrier and how radionuclides are $a b-$ sorbed by gels and clay minerals.

The first session (co-chaired by J.H. Thomassin, France) was devoted to hydrosilicate gels and early phase crystallization. Woignier (France) had studied the structural transformation of gel using smallangle neutron scattering during the densification process. He showed that the fractal cluster strongly diminishes without any significant modification of the fractal dimension.

The kinetics of gel formation, one of the most important parameters for nuclear safety, was studied in two different ways: alteration of archeological glasses in dated soils (Thomassin, France) and hydrothermal reactions in cements and concretes (Savage, United Kingdom). Gels produced by experimental alteration of R7T7 nuclear glass are unstable. Using TEM observations on ultrathin sections, Crovisier et al. (France) showed the presence of early phyllosilicate crystals even in the short duration runs. Such recrystallizations were studied in natural environments by Levy (U.S.A.), who demonstrated that lowtemperature alteration of glassy volcanic rocks produces different crystalline phases. Several papers (Creach and $\mathrm{Ma}$ gonthier, and Paulus et al., France) described the retention of radionuclides by gels.

The second session (co-chaired by $B$. Velde, France) was devoted to clay minerals in experimental and natural environments. Emphasis was put on the kinetics of reactions as well as the growth mechanisms of phyllosilicates, the hot topics now in clay science. Three invited papers introduced the session. Srodon (Poland) showed how chemical composition and crystal shape change in the course of illitization of smectite in betonites. Whitney (U.S.A.) described how smectite (mostly from betonites) reacts in experimental systems at elevated temperatures. Velde (France) demonstrated that natural illite/ smectite mixed-layer mineral series in digenetic rock formations are composed of two populations of particles that grow together with increasing temperature conditions. The kinetics of the reactions was calculated. This conference introduced several communications devoted to the kinetics of clay mineral reactions in experimental systems (Cathelineau et al. and Bouchet et al., France; Linares et al., Spain) and natural occurrences (Izquierdo et al., Mexico).

The third session, on crystallo-chemistry of clay minerals, was co-chaired by A. Baronnet and A. Manceau (France). Baronnet, using HRTEM observations, reported on crystal growth and transformation mechanisms of sheet silicates. Inoue (Japan) showed how smectite crystals change to illite by dissolution-crystallization proc- 
esses in natural environments. Decarreau (France) gave an accurate definition of a true solid solution in smectites; he particularly studied their octahedral sheet using spectroscopic methods. These three invited papers introduced a set of communications on clay reactivity under thermal activation (Ruck et al., Bruno et al., and Mosser et al., France; Balek et al., Czechoslovakia; and Cuevas and Leguey, Spain).

An invited paper by A. Manceau (France) introduced the last main point of the symposium: sorption of trace elements on a mineral/water interface. Using $x$-ray absorption spectroscopy, Manceau showed how surface reactions proceed. Several papers reported on various absorption experiments (Stammos et al. and Pitsch et al., France; Bors and Gorny, Germany).

The symposium brought together specialists from different disciplines confronted with nuclear waste problems, introducing a new form (for the clay scientists) of scientific exchange between fundamentalists and applied engineers. The participants all considered it quite exciting to look for the concrete consequences of theoretical studies.

Report provided by A. Meunier.

\section{Solid-State Chemistry of Actinides}

Chair: J.P. Adloff, Centre de Recherches Nucléaires, Lab. de Chimie Nucléaire, BP. \#20, 67037 Strasbourg, France.

This symposium was co-chaired by J. Fuger, Institute for Transuranium Elements, CBC Karlsruhe, Germany. It was limited to a half-day, joint session with the Symposium on the Scientific Basis for Nuclear Waste Management. Both symposia had about the same attendance. Four invited papers were presented. L.R. Morss (Argonne National Laboratory) reported on the preparation and characterization of fluorite-related complex oxides of rare earths and actinides which, owing to their high chemical stability and high resistance to radiation damage, are interesting hosts for the disposal of +4 actinide ions. The importance of the transuranium solids in solubility studies for nuclear waste repositories was demonstrated by $\mathrm{H}$. Nitsche (Lawrence Berkeley Laboratory). The application of EXAFS and XANES in the structural analysis of compounds of Th, U, $\mathrm{Np}$, and Am was discussed by G. Kaindl (Freie Universität, Berlin, Germany). The consequences of nuclear recoil following $\alpha$ decay in solid actinide compounds were reviewed by K. Roessler (Research Center Jülich). Contributed papers dealt with the thermodynamic properties of actinide hydroxides, the mechanisms of the retardation of uranium migration, the chemistry of uranium upon sorption onto montmorillonite, and the effects of the degradation of organic materials in the similar field of a waste repository. Investigations into the sorption of actinides onto silica in the presence of humic acids and into the formation constants of actinide compounds were also presented.

Actinide elements, because of their long half-lives are of major concern in nuclear waste management. The symposium focused on actinide compounds with properties compatible with storage conditions that must ensure confinement during many thousands of years. The behavior of actinides and fission products in the case of release had been the topic of a conference closely related to the Symposium on $\mathrm{Nu}$ clear Waste Management, held in Spain two weeks before the Strasbourg meeting. The proceedings of this Third Conference on Chemistry and Migration Behavior of Actinides and Fission Products in the Geosphere will appear in 1992 in a special issue of the journal, Radiochimica Acta.

Report provided by J.P. Adloff.

\section{Chemistry of Cements for Nuclear Applications}

Chair: P. Barret, Université de Bourgogne, Lab. de Recherche sur la Réactivite des Solides, BP. 138, 21004 Dijon, France.

In previous MRS symposia on the Scientific Basis for Nuclear Waste Management, various modes of nuclear waste immobilization were included in the same congress. For the first time, all the works dealing with the nuclear applications in cement chemistry were brought together in a separate congress, this symposium on the chemistry of cements for nuclear applications, because immobilization of low and intermediate level radioactive waste in cement has become increasingly important.

About 80 participants attended the symposium; 10 were authors of invited papers and 33 gave oral presentations. These participants were of 15 different nationalities and came from universities, industry, and atomic research centers. One of the major problems studied, related to the immobilization of nuclear waste in cement matrices, was the release of radionuclides into the environment. Cementation systems based on blends of ordinary Portland cement, blast furnace slag and pulverized fuel ash appeared likely to play an important role in immobilizing radionuclides.
Studies of the effectiveness of immobilization by leach testing were complemented by specific measurements of diffusion rates of radioisotopes in cement matrices, including the diffusion of gaseous and aqueous species. Diffusivityporosity-permeability relationships have been set up, and internal chemistry $\mathrm{pH}$ and Eh functions and their time dependence have been taken into account in order to favor the formation of most insoluble radionuclide compounds in the cement matrices.

The durability of cement matrices was considered. In underground repositories containing radwastes, sulfates may occur in both groundwater and water streams. Sulfate attack on concrete is known to be destructive. A model has been applied in performance assessment studies to repositories for low and intermediate level radioactive waste. On the other hand, appropriate experiments have been performed to predict concrete expansion in connection with the mode of formation and the crystalline morphology of AFt, which determine whether $\mathrm{AFt}$ is expansive or not.

Many other aspects, such as the performances of cement in the repository environment, the effect of high local temperature, the potential of biodegradation and the impact of radiation on cement, were discussed.

The immobilization of radwaste in cement has led to many technological and fundamental studies resulting in a better understanding of the chemical interactions between waste and cement matrices and in more general terms, of the chemistry of cements.

Report provided by P. Barret.

\section{Nuclear Materials for Fission Reactors}

Chairs: H. Matzke, European Institute for Transuranium Elements, JEC, CEC, Postfach 2340, W-7500 Karlsruhe, Germany; G. Schumacher, Kernforschungszentrum Karlsruhe, Institut für Neutronenphysik und Reaktorentechnik, Postfach 2340, W-7500 Karlsruhe, Germany.

The symposium on Nuclear Materials for Fission Reactors aimed at bringing together scientists interested in the fabrication of new nuclear fuels, basic research of nuclear materials, and their application and technology as well as in computer codes and modeling for fuel behavior. Exchange of views, ideas, and new results with the scientists and engineers dealing with specific questions of nuclear waste 
management was achieved by organizing a joint session on nuclear fuels as waste matrices and a joint poster session. Many participants took the opportunity to attend lectures at both symposia.

A total of 52 presentations were grouped into 4 sessions: Fuel Fabrication and Performance, Reactor Safety, Basic Properties of Nuclear Fuel Materials, and Modeling.

Emphasis was placed on the progress made in the development of non-oxide fuels besides reporting the progress made on the more conventional oxide fuels. The two current large reactor safety programs, CORA and PHEBUS-FP, were described in invited papers. Some 20 contributions dealt with the basic property measurements, and eight contributions presented the present state of fuel performance modeling. The performance of today's nuclear fuel, hence $U_{\mathrm{O}_{2}}$, under long irradiation times (hence high burnup) was the key point of seven presentations, with particular emphasis on the recently observed phe-

\section{Advanced Metalization for ULSI Applications in 1992}

(formerly Workshop on Tungsten and Other Advanced Metals for ULSI Applications)

October 20-22, 1992, in Phoenix, Arizona

\section{Announcement and Call for Papers}

The conference is the ninth in a series organized to bring together active researchers in the field of advanced metalization for IC applications.

Papers are solicited on topics in the deposition and applications of CVD W, Cu, TiN, Al, and conventional metalization, including:

Deposition techniques

CVD modeling

Deposition kinetics

CVD precursor developments for $\mathrm{Cu}, \mathrm{Al}, \mathrm{TiN}$, and $W$

Nucleation and compatibility studies

Adhesion to oxides

Grain refinement and control

Fundamental surface chemistry

Selectivity issues in advanced metals

Film properties (physical, chemical, electrical)

Film/substrate interaction

CVD reactor design enhancements

Wafer temperature measurement and control

Process control/manufacturability

\section{Abstracts are due July 1, 1992}

Send abstracts (at least 500 words, with an additional page of figures) to Fabio Pintchovski, Motorola, Inc., APRDL, K10, 3501 Ed Bluestein Blvd., Austin, TX 78762. Include author's name, affiliation, mailing address, and phone and fax numbers on abstract.

\section{For an announcement:}

Call (510)642-4151, fax (510) 643-8683, e-mail ceeunex@garnet.berkeley.edu, or write to Continuing Education in Engineering, University Extension, University of California, 2223 Fulton St., Berkeley, CA 94720.

\section{Continuing Education in Engineering, University Extension, UNIVERSITY OF CALIFORNIA, BERKELEY}

nomenon of grain subdivision in the cold part of the oxide fuel at high burnup, the so-called RIM effect.

The proceedings of this symposium will be published as a special volume of the Journal of Nuclear Materials.

Report provided by H.J. Matzke and G. Schumacher.

\section{Chemical and Physical \\ Modifications Induced by Irradiation in Glasses}

Chair: P. Mazzoldi, Dipartimento Di Fisica "Galileo Galilei," Università Degli Studi di Padova, Via F. Marzoli 8, 35131 Padova, Italy.

The aim of this symposium was to focus on the basic research and application trends of ion implantation in glasses. About 30 people participated in the meeting with the presentation of 12 contributions and four invited talks. The invited papers underlined the effects of ion implantation on the modifications of optical (Townsend, Surrey University), mechanical (G.W. Arnold, Sandia National Laboratories), and chemical (J.C. Dran, Orsay Laboratories, and C. Battaglin, Padova University) properties. New ideas were presented on the possible applications of implantation techniques in the field of optoelectronics, particularly for preferential etching processes. The results on the formation of oxinitrides by double implantation in glasses reveal an interesting perspective. There were fewer participants compared with the previous symposia, probably due to the organization in June 1991 of the International Conference on Radiation Effects in Insulators (REI). The proceedings will be published by Elsevier.

Report provided by P. Mazzoldi.

Information for the 1991 E-MRS Fall Meeting report came from the E-MRS Newsletter, No. 4, Winter 1991-1992, p. 3-9.

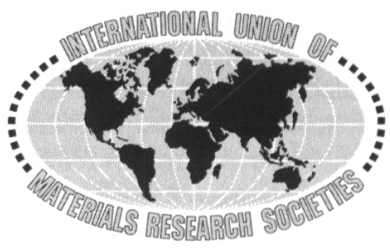

\section{E-MRS Fall Meeting- 3rd European East-West Conference on Materials and Processes}

Strasbourg, France

November 3 - 6, 1992

See Calendar listing in this issue. 